\title{
MEKANISME PERTAHANAN DAN KONFLIK TOKOH DALAM NOVEL SI ANAK BADAI KARYA TERE LIYE
}

\author{
Agustiani Nur Afrikah', Ririn Setyorini² \\ Program Studi Pendidikan Bahasa Indonesia, FIKIP, Universitas Peradaban \\ ${ }^{1}$ fikaafrikah@gmail.com ${ }^{l}{ }^{2}$ ririnsetyorini91@gmail.com
}

\begin{abstract}
Abstrak
Penelitian ini bertujuan untuk mendeskripsikan dan menjelaskan mekanisme pertahanan dan konflik yang terdapat dalam novel Si Anak Badai karya Tere Liye. Metode yang digunakan dalam penelitian ini ialah metode deskriptif kualitatif dengan tujuan untuk menjelaskan dan mendeskripsikan mekanisme pertahanan dan konflik yang terdapat dalam novel Si Anak Badai karya Tere Liye. Teknik pengumpulan data yang digunakan dalam penelitian ini yaitu teknik studi pustaka, baca, dan catat. Teknik studi pustaka digunakan untuk mendapatkan data dalam novel $S i$ Anak Badai. Teknik baca dan catat dilakukan untuk mengetahui dan mendapatkan data terkait kutipan atau wacana yang menunjukkan adanya mekanisme pertahanan dan konflik yang tertuang di novel Si Anak Badai. Mekanisme pertahanan dan konflik yang terdapat dalam novel Si Anak Badai meliputi represi, sublimasi, rasionalisasi, pengalihan, reaksi formasi, dan proyeksi.
\end{abstract}

Kata Kunci: Mekanisme Pertahanan dan Konflik, Tinjauan Psikologi Sastra

\begin{abstract}
This study aims to describe and explain the defense and conflict mechanisms contained in the novel Si Anak Badai creation Tere Liye. The method used in this research is a qualitative descriptive method with the aim of explaining and describing the defense and conflict mechanisms contained in the novel Si Anak Badai creation Tere Liye. Data collection techniques used in this research are literature study techniques, reading, and taking notes. Literature study techniques are used to obtain data in the novel Si Anak Badai. Reading and note-taking techniques are used to find out and obtain data related to quotations or discourses that show the existence of a defense and conflict mechanisms contained in the novel Si Anak Badai. Defense and conflict mechanisms contained in the novel Si Anak Badai includes repression, sublimation, rationalization, formation reactions, diversions, and projections.
\end{abstract}

Keywords: Defense and Conflict Mechanisms, Areview of Literary Psychology

\section{PENDAHULUAN}

Novel sebagai karya sastra yang di dalamnya memuat sebuah kisah atau cerita, dan di dalam novel tokoh sebagai pembangun dalam karya sastra mempunyai peranan yang sangat penting. Melalui tokoh cerita yang ditampilkan pada novel, seorang pembaca akan mudah memahami makna yang akan disampaikan oleh pengarang dalam novel tersebut. Setiap tokoh dalam cerita mempunyai karakter yang sangat unik dan berbeda. Semua karakter akan membangun suatu konflik dan konflik tersebut akan semakin meningkat sehingga menciptakan sebuah karya yang menarik untuk dapat dikaji, dalam 
menganalisis sebuah karya seperti novel, dapat dilakukan dengan berbagai disiplin ilmu yang salah satunya adalah ilmu psikologi sastra.

Psikologi sastra terlahir untuk salah satu macam kajian sastra yang dipergunakan sebagai membaca serta mengaplikasikan karya sastra, penulis karya sastra dan pembacanya telah memakai beberapa rancangan serta kerangka teori yang tertuang pada psikologi (Wiyatmi, 2011: 6). Jadi, psikologi sastra ialah gabungan antara psikologi dan sastra yang di dalamnya memuat kajian dalam ilmu sastra yang mempelajari mengenai kejiwaan yang ada pada diri manusia. Psikologi sastra diciptakan untuk mengetahui rasa, jiwa, dan kecemasan yang dialami oleh seseorang.

Mempelajari psikologi sastra sebenarnya sama halnya dengan mempelajari manusia dari sisi dalam, sehingga psikologi sastra merupakan satu buah bidang studi antara sastra dengan psikologi, Minderop (2010: 59). Mungkin aspek "dalam" ini yang acap kali bersifat subjektif, yang membuat para pemerhati sastra menganggapnya berat. Daya tarik psikologi sastra ialah pada masalah manusia yang melukiskan potret jiwa. Tidak hanya jiwa sendiri yang muncul dalam sastra, tetapi juga bisa mewakili jiwa orang lain. Setiap pengarang kerap menambahkan pengalaman sendiri dalam karyanya dan pengalaman pengarang itu sering pula dialami oleh orang lain.

Permasalahan yang bertema psikologi merupakan permasalahan yang banyak dituangkan pengarang dalam karya tulisnya. Hal ini disebabkan karena psikologi membicarakan tentang tingkah laku manusia. Selain itu, unsur-unsur psikologi dalam novel merupakan manifestasi kejiwaan seorang pengarang. Oleh karena itu, pendekatan psikologi merupakan salah satu pendekatan yang dapat digunakan dalam menganalisis sebuah karya sastra (Afrianti dkk., 2012: 195).

Psikologi tidak mempelajari jiwa atau mental itu secara langsung karena sifatnya yang sangat abstrak, tetapi psikologi sangat membatasi pada manifestasi dan ekspresi jiwa atau mental tersebut, yakni yang berupa tingkah laku dan proses atau kegiatannya, sehingga psikologi dapat didefinisikan sebagai ilmu pengetahuan yang mempelajari tingkah laku dan proses mental dari seseorang (Zaviera, 2017: 19).

Terdapat lima penelitian yang relevan, pertama, Halifah (2015), persamaan penelitian Halifah dengan penelitian ini yaitu sama-sama mengkaji mekanisme pertahanan dan konflik pada tokoh utama, perbedaannya yaitu kajian pada penelitian ini mengkaji novel Si Anak Badai, sedangkan Halifah mengkaji novel Lentera Mustika. Kedua, Rohman (2019), persamaan penelitian Rohman dengan penelitian ini yaitu samasama mengkaji mekanisme pertahanan yang terdapat pada novel, perbedaannya yaitu mengkaji psikologi yang terdapat pada tokoh utama, sedangkan penelitian ini mengkaji mekanisme pertahanan dan konflik yang terdapat pada tokoh.

Ketiga, Mauludya dkk. (2018), persamaan penelitian Mauludya, dkk. dengan penelitian ini yaitu sama-sama mengkaji novel yang memiliki mekanisme pertahanan, sedangkan perbedaannya Mauludya, dkk. mengkaji novel yang bercerita mengenai perempuan di negara Jepang. Keempat, Piliang (2016), persamaan penelitian milik Piliang dengan penelitian ini yaitu sama-sama mengkaji akan adanya mekanisme pertahanan yang terdapat dalam tokoh, sedangkan perbedaannya yaitu Piliang mengkaji cerpen, sedangkan penelitian ini mengkaji novel. Kelima, Martono dkk. (2016), persamaan penelitian Martono dkk. dengan penelitian ini yaitu sama dengan penelitian lain yakni novel, sedangkan perbedaannya Martono dkk. mengkaji tokoh transgender yang memiliki mekanisme pertahanan ego, sedangkan penelitian ini mengkaji tokoh yang akan memiliki mekanisme pertahanan dan konflik. 
Psikologi sastra sendiri merupakan cabang ilmu yang mempunyai kreativitas serta sifatnya tiap bidang studi. Psikologi sastra bertujuan untuk mempelajari tanda-tanda kebatinan yang tercantum pada sebuah karya. Novel Si Anak Badai adalah novel yang mengisahkan tentang seorang anak yang hidup bersama bunyi saluran sungai, getaran permukaan laut, serta tiruan ombak laut. Si Anak Badai yang banyak semangat serta kegigihan membela yang telah menjadi kepunyaan mereka yaitu, mempertahankan kampungnya agar tidak digusur dan dijadikan pelabuhan. Hal ini ialah bagaimana memperlihatkan mekanisme pertahanan yang kejadiannya dalam diri pemeran dalam novel Si Anak Badai. Tokoh-tokoh pada novel yang melakukan tindakan melestarikan kampung yang akan di gusur dan dijadikan pelabuhan serta geng Si Anak Badai yang melakukan berbagai cara untuk menemukan bukti agar kampungnya tidak jadi di gusur.

Selain itu, dalam psikologi sastra terdapat mekanisme pertahanan dan konflik. Mekanisme pertahanan terjadi karena adanya dorongan atau perasaan yang beralih untuk mencari objek pengganti. Minderop (2010: 29) menggunakan istilah mekanisme pertahanan mengacu pada proses alam bawah sadar seseorang yang mempertahankannya terhadap anxitas, mekanisme ini melindunginya dari ancaman-ancaman eksternal atau adanya implus-implus yang timbul dari anxitas internal dengan mendistorsi realitas menggunakan berbagai cara.

Pertahanan yang paling primitif yaitu ancaman-ancaman dari luar ialah denial of reality (penolakan realitas) ketika si individu mencoba menolak realitas yang mengganggu dengan penolakan. Jadi, mekanisme pertahanan merupakan proses dari alam bawah sadar yang terjadi pada diri manusia dan manusia mempertahankan untuk kecemasan. Pada penelitian ini, novel Si Anak Badai karya Tere Liye dianalisis terkait mekanisme pertahanan dan konflik. Mekanisme pertahanan dan konflik yang meliputi enam mekanisme, yaitu rasionalisasi, sublimasi, rekasi formasi, represi, proyeksi, dan pengalihan.

\section{METODE PENELITIAN}

Penelitian ini merupakan jenis penelitian deskriptif kualitatif Sugiyono (2017: 9) mengemukakan tentang penelitian kualitatif sebagai metode penelitian yang berlandaskan pada filsafat pos positivisme, digunakan untuk meneliti pada kondisi objek yang alamiah, (sebagai lawannya adalah eksperimen) di mana peneliti adalah sebagai instrumen kunci, teknik pengumpulan data dilakukan secara triangulasi (gabungan), analisis data bersifat induktif/kualitatif, dan hasil penelitian kualitatif lebih menekankan makna dari pada generalisasi. Penelitian deskriptif kualitatif bertujuan untuk menjelaskan dan mendeskripsikan mekanisme pertahanan dan konflik yang terdapat dalam novel Si Anak Badai karya Tere Liye.

Teknik pengumpulan data yang digunakan dalam penelitian ini, yaitu teknik studi pustaka, baca, dan catat. Teknik studi pustaka digunakan untuk mendapatkan data dalam novel Si Anak Badai, buku-buku referensi, dan artikel jurnal relevan. Selanjutnya, teknik baca dan catat dilakukan untuk mengetahui dan mendapatkan data terkait kutipan atau wacana yang menunjukkan adanya mekanisme pertahanan dan konflik yang tertuang di novel Si Anak Badai.

\section{HASIL DAN PEMBAHASAN}

Mekanisme pertahanan dan konflik dalam novel Si Anak Badai karya Tere Liye yang terdapat pada tokoh Zaenal, Awang, Malim, dan Ode meliputi represi, sublimasi, 
rasionalisasi, pengalihan, reaksi formasi dan proyeksi. Berikut adalah mekanisme pertahanan dan konflik pada novel Si Anak Badai.

\section{Represi}

Represi merupakan sebuah rangkaian diri yang menggunakan keteguhan sebagai penekanan semua sesuatu yang meliputi naluri, kesadaran, gagasan dan akal yang bisa mengakibatkan kekhawatiran dari luar kesadaran. Dalam novel Si Anak Badai karya Tere Liye ditemukan represi yang terdapat dalam tokoh yang mengakibatkan kekhawatiran pada tokoh.

Represi dalam novel Si Anak Badai karya Tere Liye ditemukan empat kutipan cerita. Kutipan-kutipan tersebut terdapat pada halaman 154, 191, 283, dan 287. Tokohtokoh yang mengalami represi antara lain: Zaenal, Awang, Ode dan Malim. Berikut beberapa kutipan yang menunjukkan adanya represi dalam tokoh tersebut.

"Mustahil! Pak Alex itu keras kepala. Aku khawatir dia malah mempercepat mengusir kita dari sekolah."

Kami berempat terdiam.

"Bagaimana kalau nanti siang kita ke dermaga?" Aku memberi usul. Dari pada menebak-nebak apa yang terjadi, lebih baik kami mencari informasi. (Liye, 2019: 283)

Berdasarkan kutipan pada halaman 283 menjelaskan bahwa mekanisme pertahanan represi yang ada pada tokoh Zaenal saat Zaenal khawatir Pak Alex akan mempercepat pengusiran dari sekolah. Tindakan yang dilakukan Zaenal adalah mengajak teman-temannya untuk ke dermaga sambil mencari informasi untuk mengurangi rasa kecemasannya.

"Benar dugaanku. Kami susah-susah memikirkan kau, eh kau malah enak-enakan tidur di sini." Ode tidak menjawab pertanyaan Malim.

"Siapa suruh kalian memikirkanku? Lagi pula, siapa yang minta kalian datang ke sini?"

"Ini bale-bale milik umum, Lim. Terserah kami mau datang ke sini." Ode tidak mau kalah. (Liye, 2019: 191)

Berdasarkan kutipan pada halaman 191 menjelaskan bahwa mekanisme pertahanan represi terhadap tokoh Ode. Sebenarnya Ode sangat sebal karena Malim sudah di pikirkan tetapi malah santai, enak-enakan tidur. Tindakan yang dilakukan oleh Ode adalah tidak mau kalah dan terus melawan Malim.

"Aku juga kesal sama mereka. Kalau aku alien, sudah aku gigit mereka." Awang memandang lurus. (Liye, 2019: 287)

Kutipan yang terdapat pada halaman 287 menjelaskan bahwa mekanisme pertahanan represi yang terdapat pada tokoh Awang adalah saat Awang merasa cemas dan kesal tetapi rasa itu membuat diri Awang menjadi lebih nyaman dengan mengatai dirinya sebagai alien.

"Oi, kalau kau ragu dengan kemampuanku, ikut saja nanti malam. Kita memancing!” Malim mengeluarkan tantangan. (Liye, 2019: 154) 
Dalam kutipan tersebut menjelaskan bahwa mekanisme pertahanan represi pada tokoh Malim adalah saat Malim menekankan bahwa teman-temannya ragu akan kemampuannya, dan Malim ingin membuktikan kemampuannya dalam memancing. Represi yang dialami oleh tokoh Malim yaitu, saat Malim menekankan kecemasan pada Malim saat dirinya menghindari perasaan cemas dan mendapatkan sebuah kenyamanan yaitu mengajak teman-temannya untuk memancing dan memperlihatkan kemampuannya dalam memancing.

\section{Sublimasi}

Sublimasi merupakan tindakan yang bermanfaat dan menghindari perasaan yang tidak nyaman, atau juga dapat dilakukan tindakan pengalihan untuk menghindari kecemasan yang dialami oleh seseorang, agar orang tersebut tidak berfikir negatif. Pada novel Si Anak Badai karya Tere Liye ditemukan adanya sublimasi yang terdapat dalam tokoh.

Sublimasi dalam novel Si Anak Badai karya Tere Liye terdapat empat kutipan cerita. Kutipan-kutipan tersebut terdapat pada halaman 30, 35, 43, dan 153. Tokoh-tokoh yang mengalami adanya sublimasi yaitu Zaenal, Awang, Ode dan Malim. Berikut beberapa kutipan yang menunjukkan adanya sublimasi dalam novel Si Anak Badai karya Tere Liye.

"Mamak menyuruh kita bertanggung jawab. Aku tak ingin pulang sebelum persoalannya berakhir. Dapat meluas urusannya. Kita bisa dihukum tidur di teras rumah. Kalau kau tidak mau ikut, biar aku saja." Tanpa menunggu reaksi Fatah, aku mengulurkan tangan, meminta buku tulis dan pensil yang ada padanya. (Liye, 2019: 43)

Dalam kutipan yang ditunjukkan pada halaman 43 menjelaskan bahwa mekanisme pertahanan sublimasi karena di sini Zaenal telah bicara pada Fatah untuk tidak akan pulang sebelum semua urusannya selesai. Zaenal bertindak untuk tetap pergi, Zaenal mengulurkan tangan untuk meminta buku tulis dan pensil yang ada pada Fatah.

"Tidak, aku udah sarapan hingga kenyang. Disengaja demikian agar aku dapat menabung. Banyak sekali kebutuhan yang mau kubeli." (Liye, 2019: 30)

Kutipan pada halaman 30 menjelaskan bahwa mekanisme pertahanan sublimasi yang terdapat pada tokoh Ode adalah saat Ode tidak ingin ikut jajan dan sengaja sarapan sampai kenyang agar bisa menabung untuk membeli keperluan yang dibutuhkan oleh Ode. Sublimasi dalam tokoh Ode melakukan tindakan yang bermanfaat dengan cara menghindari jajan untuk dapat menabung.

"Baiklah kalau begitu. Kau tenang saja, Tia. Sebelum lonceng tanda istirahat selesai, aku akan membawa kembali bolpoin kesayangan kau itu." (Liye, 2019: 35)

Kutipan pada halaman 35 menjelaskan bahwa mekanisme pertahanan sublimasi pada tokoh awang terlihat pada saat Awang ingin mengambil bolpoin Tia di dasar sungai, Awang yang memiliki tindakan yang bermanfaat untuk menghindari perasaan tidak nyaman yang ada pada diri Awang untuk menolong Tia.

"Bukan hitungan matematika, Kawan. Ini hitung-hitungan yang diwariskan para leluhur, berdasarkan letak bulan dan rasi bintang. Jauh lebih sukar daripada matematika." Penuh lagak Malim menerangkan. (Liye, 2019: 153) 
Kutipan di atas menjelaskan bahwa mekanisme pertahanan sublimasi yang terdapat pada tokoh Malim yaitu saat Malim mengetahui akan hitung-hitungan yang diwariskan para leluhur, sublimasi merupakan mekanisme yang memiliki nilai sosial yang tinggi dan tokoh Malim memiliki mekanisme sublimasi, seperti yang sudah disebutkan yaitu, saat tokoh Malim mengetahui akan adanya hitung-hitungan yang diwariskan oleh para leluhur.

\section{Rasionalisasi}

Rasionalisasi merupakan mekanisme pertahanan diri yang dilakukan oleh individu sebagai pencarian dasar yang pas untuk menerangkan rasa sadar serta macam luapan perasaan yang dimiliki. Dalam novel Si Anak Badai karya Tere Liye ditemukan tokoh yang mengalami rasionalisasi.

Rasionalisasi dalam novel Si Anak Badai karya Tere Liye ditemukan empat kutipan cerita. Kutipan-kutipan tersebut terdapat pada halaman 49, 104-105, 196, dan 266. Berikut kutipan yang menunjukkan adanya rasionalisasi dalam novel Si Anak Badai karya Tere Liye.

"Oi!” Aku menoleh sebal karena Ode menarik kakiku. "Apa yang kau lakukan?

Kau mau curang?"

"Siapa yang curang? Jangan asal tuduh kau!" Ode meminjam kalimat Malim." Lagi pula, tadi Malim juga begitu." Dia nyengir tanpa dosa, kepalanya muncul tenggelam, terus berenang menyalipku. (Liye, 2019: 104-105)

Berdasarkan kutipan pada halaman 104-105 menjelaskan bahwa mekanisme pertahanan rasionalisasi yang dialami oleh Zaenal yang sempat sebal karena Ode menarik kakinya saat berenang. Zaenal berbicara pada Ode apa yang Ode lakukan, Ode mau curang agar bisa menang dan menjadi juara menyelam, dan itu merupakan tindakan Zaenal untuk mengurangi kecewa ketika Ode menarik kakinya dan mau curang.

"Kau macam kucing beranak saja, Han, selalu pindah-pindah tempat." Ode berdiri sambil berkacak pinggang. (Liye, 2019: 49)

Dalam kutipan tersebut menjelaskan bahwa mekanisme pertahanan rasionalisasi tokoh Ode adalah saat memilih keputusan bahwa Rahan macam kucing beranak dengan berpindah-pindah tempat. Ode meninggalkan hal yang tidak perlu dilakukan seperti berkacak pinggang.

"Besok-besok kami akan datang sambil membawa rebana. Biar kau tidak bosan sendirian di bale ini." Awang kembali bicara." (Liye, 2019: 196)

Dalam kutipan tersebut menjelaskan bahwa mekanisme pertahanan rasionalisasi terhadap tokoh Awang. Saat Awang memilih untuk memutuskan bahwa kalau datang menemui Malim dengan membawa rebana agar Malim tidak bosan. Rasionalisasi yang dialami oleh Awang adalah suatu keputusan yang menjadi prioritas yang diambil oleh dirinya sendiri.

"Mereka semua sudah disuap." Malim berkata sambil melemparkan potongan roti ke permukaan sungai. Ikan-ikan kecil langsung menggerubuti. (Liye, 2019: 266) 
Dalam kutipan tersebut menjelaskan bahwa mekanisme pertahanan rasionalisasi pada tokoh Malim yaitu, Malim memilih keputusan yang harus di prioritaskan seperti halnya dengan menuduh pejabat yang telah disuap. Karena Malim memperlihatkan rasionalisasi yang ada pada dirinya.

\section{Pengalihan}

Pengalihan merupakan bentuk pertahanan diri dalam menghadapi kecemasan dengan cara memindahkan objek yang sangat mengancam menuju objek yang membuat individu menjadi lebih nyaman. Dalam novel Si Anak Badai karya Tere Liye ditemukan adanya pengalihan yang terdapat pada tokoh.

Pengalihan dalam novel Si Anak Badai karya Tere Liye ditemukan empat kutipan cerita. Kutipan-kutipan tersebut terdapat pada halaman 40, 167, 276, dan 306. Tokoh yang mengalami akan adanya pengalihan antara lain: Zaenal, Awang, Malim, dan Ode. Berikut adalah kutipan yang menunjukkan adanya pengalihan dalam novel Si Anak Badai karya Tere Liye.

"Bukankah kau yang mengukur?" Aku tidak mau disalahkan. Enak saja.

"Aku menyebutkan ukuran yang benar. Kak Za-lah yang salah mencatat."

"Aku mencatat apa yang kau katakan, Fat." (Liye, 2019: 40)

Berdasarkan kutipan di atas menjelaskan bahwa mekanisme pertahanan pengalihan yang terdapat pada tokoh Zaenal adalah ketika Zaenal membantah bahwa bukan dia yang mengukurnya dan tidak mau disalahkan. Karena Zaenal mengalami kesalahan dan membuat adiknya dijadikan sebagai sumber permasalahan makan dari itu Zaenal mengalihkan kesalahannya terhadap adiknya.

“Omong-omong, bagaimana ikan bakar tadi siang, Pak?" Ode sengaja mengulur waktu. (Liye, 2019: 306)

Kutipan di atas menjelaskan bahwa mekanisme pertahanan pengalihan yang terdapat pada tokoh Ode saat akan mengulur waktu dengan bertanya kepada Tukang Pukul dengan cara menarik perhatian bertanya tentang ikan bakar.

"Buat menghilangkan jejak," kata Awang saat mengusulkan mencuri perahu Pak

Kapten. (Liye, 2019: 276)

Kutipan di atas menjelaskan bahwa mekanisme pertahanan pengalihan yang terdapat pada tokoh Awang ketika ia menyarankan untuk menghilangkan jejak dengan mencuri perahu Pak Kapten. Dan menjadikan perahu Pak Kapten sebagai sumber permasalahannya.

"Jelas maksudnya, Paman. Cakalang ini bisa dibeli jika ikan di perahuku ini ikut dibeli." (Liye, 2019: 167)

Berdasarkan kutipan di atas menjelaskan bahwa mekanisme pertahanan pengalihan yang terjadi pada tokoh Malim yaitu, saat Malim mengaku bahwa ikan cakalang tersebut adalah milik dirinya. Untuk memperjelas pengalihan yang terdapat pada tokoh Malim. Malim memiliki sesuatu hal yang ia hadapi seperti ingin menjual ikan yang ia tangkap tetapi Malim juga mengaku-ngaku bahwa ikan cakalang adalah miliknya supaya Pak pengepul mau membeli ikan yang Malim tangkap, hal tersebut merupakan mekanisme pertahanan pengalihan yang terdapat pada tokoh Malim. 


\section{Reaksi Formasi}

Reaksi formasi ialah tindakan defensif dengan cara mengganti perasaan yang menimbulkan kecemasan dengan perasaan lawan atau kebalikannya dalam kesadaran. Dalam novel Si Anak Badai karya Tere Liye ditemukan adanya reaksi formasi yang terdapat dalam tokoh novel tersebut.

Reaksi formasi dalam novel Si Anak Badai karya Tere Liye terdapat empat kutipan cerita. Kutipan-kutipan tersebut terdapat pada halaman 13, 36-37, 186, dan 230. Tokoh-tokoh yang mengalami akan reaksi formasi antara lain: Zaenal, Awang, Ode dan Malim. Berikut adalah kutipan yang menunjukkan adanya reaksi formasi yang terdapat dalam tokoh novel Si Anak Badai karya Tere Liye.

"Bagaimana kalau ada nelayan yang melintas? Atau ada kapal yang lewat dan penumpangnya bersorak-sorak melihatmu telanjang, mengira kau tuyu; sungai? Atau ada orang stasiun televisi yang lewat, kau akan masuk TV tanpa pakaian sehelai pun." Aku mengingatkan.

"Kau berlebihan, Za. Waktu kecil kita juga mandi telanjang."

“Tapi kita sudah kelas enam, Wang." (Liye, 2019: 36-37)

Dalam kutipan tersebut menjelaskan bahwa mekanisme pertahanan reaksi formasi yang dialami tokoh Zaenal yang sedang mencegah Awang untuk tidak berenang dengan telanjang. Tetapi awang bilang bahwa Zaenal terlalu berlebihan, dan Zaenal membalas dengan kata "Tapi kita sudah kelas enam, Wang." Zaenal justru menasihati Awang dengan perasaan yang dirasakannya dengan perilaku yang sama sekali berbeda.

"Panjang cerita kau, Za. Kalau kapalnya tidak berlayar, nahkoda itu bisa gabung dengan kita di sini. Menjadi anak buahku. Duduk menunggu kapal, kemudia berenang di sisi kapal sambil melambaikan tangan dan berteriak, Manowa! Manowa! Juragan! Juragan!" Ode berteriak, dengan semangat, tangannya teracung-acung. Akhirnya dia terpingkal sendiri. (Liye, 2019: 13)

Berdasarkan kutipan di atas menjelaskan bahwa mekanisme pertahanan reaksi formasi yang terdapat dalam tokoh Ode adalah saat mengahsilkan kecemasan dengan berkata kalau kapal tidak berlayar, nahkodanya bisa bergabung dengannya dan pada kutipan tersebut untuk mencegah sifat antisosial pada Ode.

"Aku juga percaya. Tapi Pak Kapten sengaja disingkirkan dari kampung kita agar tidak ada lagi yang menghalangi pembangunan pelabuhan. Tidak lama lagi pelabuhan akan dibangun. Rumah-rumah akan dirobohkan. Kita semua terpaksa pindah. Kalian lihat film yang kita tonton di layar tancap? Nasib kampung kita akan sama seperti film itu. Maka boleh jadi ini adalah saat terakhir kita melaut bersama." Panjang sekali kalimat Awang. (Liye, 2019: 230)

Berdasarkan kutipan di atas menjelaskan bahwa mekanisme pertahanan reaksi formasi yang terdapat pada tokoh Awang adalah ketika Awang bicara panjang lebar tentang kampungnya dan Pak Kapten. Awang yang berperilaku menghasilkan kecemasan pada dirinya untuk mencegah sifatnya yang anti sosial. 


\begin{abstract}
"Cita-citaku menjadi saudagar besar. Itu tidak butuh sekolah. Aku akan mengumpulkan uang sedikit demi sedikit. Besok kubelikan kapal-kapal besar. Kapal kontainer, Kapal pesiar. Aku akan menjadi pemilik banyak kapal. Itu semua tidak perlu sekolah. Besok-besok, anak-anak kau, Ode, Awang, berenang-renang menghampiri kapalku, menunggu koin dijatuhkan. Penumpang kapal tidak bertanya tentang ijazah. Ikan di lautan juga tidak bertanya." Malim bicara penuh keyakinan. (Liye, 2019: 186)
\end{abstract}

Kutipan di atas menjelaskan bahwa mekanisme pertahanan reaksi formasi yang terdapat pada tokoh Malim yaitu, saat Malim berperilaku solah-olah dirinya tidak membutuhkan ijazah untuk menjadi saudagar besar yang memiliki banyak kapal. Malim tidak perduli akan sekolah. Reaksi formasi yang ditimbulkan pad diri Malim adalah Malim memiliki prilaku yang mengabaikan Zaenal yang tengah menasihatinya agar tidak berhenti sekolah.

\title{
Proyeksi
}

Proyeksi merupakan sikap perlindungan diri dari suatu kondisi yang sangat kritis, misalnya seperti ada seorang individu yang di kasari oleh teman, individu tersebut melawannya dengan hal yang benar, dan membela dirinya dengan melawan temannya tersebut, dalam novel Si Anak Badai karya Tere Liye terdapat tokoh yang mengalami akan adanya proyeksi yang dialami oleh para tokoh.

Proyeksi dalam novel Si Anak Badai karya Tere Liye terdapat empat kutipan cerita. Kutipan-kutipan tersebut terdapat pada halaman 50, 172, 173 dan 303. Tokohtokoh yang mengalami akan adanya mekanisme pertahanan proyeksi antara lain: Zaenal, Awang, Malim dan Ode. Berikut kutipan yang menyatakan bahwa tokoh yang mengalami proyeksi.

"Kau mau ke mana, Za?" Mamak bertanya heran karena begitu pulang dari mengaji, aku kembali pamit keluar. "Memancing di muara lagi, Mak." Aku memberi tahu. "Oi, bukankah tadi siang sudah?" Mamak tampak keberatan.

"Lagi banyak ikannya, Mak." Aku mengarang alasan.

"Oi, bukankah tadi siang sudah?” Mamak tampak keberatan.

"Lagi banyak ikannya, Mak." Aku mengarang alasan. (Liye, 2019: 303)

Kutipan di atas menjelaskan bahwa mekanisme pertahanan proyeksi. Proyeksi sama dengan pengalihan. Tokoh Zaenal tidak akan melimpahkan kesalahan pada Mamak dan selalu bilang akan memancing di muara. Zaenal mengarang alasan agar tidak di cegat oleh Mamak untuk memancing.

"Kau macam ikan mabuk tuba, Za. Ditanya bukannya menjawab malah nyengirnyengir sendiri." Ode mengambil ancang-ancang terjun. (Liye, 2019: 50)

Kutipan di atas menjelaskan bahwa mekanisme pertahan proyeksi yang terdapat pada tokoh Ode adalah ketika Ode melimpahkan kesalahan kepada Zaenal dan membuat perumpaan untuk Zaenal dengan menyebutnya macam ikan mabuk tuba.

"Aku juga minta maaf, Wak. Aku hanya ikut-ikutan menangkapnya di sungai." (Liye, 2019: 172) 
Kutipan di atas menjelaskan bahwa mekanisme pertahanan proyeksi pada tokoh Awang adalah saat dirinya meminta maaf pada Wak Sidik karena sudah ikut-ikutan menangkap tanpa mengetahui penyebabnya dengan pasti, Awang mengalami proyeksi pada saat dirinya menghadapi situasi di mana dirinya tidak mengharapkan hal tersebut.

"Aku juga ikut-ikutan datang kesini. Seharusnya aku tadi di perahu saja. Sumpah, aku tidak tahu apa-apa soal ini." Malim menjawab polos. (Liye, 2019: 173)

Dalam kutipan tersebut menjelaskan bahwa mekanisme pertahanan proyeksi pada tokoh Malim yaitu, Malim ikut-ikutan datang. Malim seraya tidak tau apa-apa dengan bersikap sok polos. Proyeksi yang terdapat pada tokoh Malim seolah menutupi akan masalah yang ia tidak ketahui.

\section{SIMPULAN}

Simpulan dari hasil penelitian tentang mekanisme pertahanan dan konflik pada novel Si Anak Badai karya Tere Liye merupakan mekanisme pertahanan dan konflik yang disebabkan oleh faktor keluarga, lingkungan, dan persahabatan. Adapun mekanisme pertahanan dan konflik terjadi pada novel Si Anak Badai karya Tere Liye meliputi tokoh Zaenal, Awang, Malim, dan Ode. Mekanisme pertahanan dan konflik yang memiliki sebuah kecemasan yang terdapat pada jiwa tokoh yang meliputi represi, sublimasi, rasionalisasi, pengalihan, reaksi formasi, dan proyeksi. Mekanisme pertahanan dan konflik itu terjadi karena adanya faktor keluarga, sahabat, dan lingkungan.

\section{DAFTAR PUSTAKA}

Martono, N., Rosa, H. T., \& Azmin, G. G. (2016). Mekanisme pertahanan ego pada tokoh transgender dalam novel Pasung Jiwa karya Okky Madasari: Suatu kajian psikologi sastra. Arkhais-Jurnal Ilmu Bahasa Dan Sastra Indonesia, 7(2), 87-92.

Halifah, N. (2015). Mekanisme pertahanan dan konflik dalam novel Lentera Mustika Karya Nisah Haron. BAHASANTODEA, 3(1), 1-11.

Liye, T. (2019). Si Anak Badai. Jakarta: Republika Penerbit.

Minderop, A. (2010). Psikologi sastra, karya sastra, metode, teori, dan contoh kasus. Jakarta: Pustaka Obor.

Mauludya, F., Sumartini, S., \& Mulyono, M. (2018). Pertahanan diri tokoh utama dalam novel Perempuan Kembang Jepun karya Lan Fang. Jurnal Sastra Indonesia, 7(1), $32-40$.

Afrianti, N., Abdurahman, A., \& Nursaid, N. (2012). Konflik batin dalam novel Moga Bunda Disayang Allah karya Tere Liye. Pendidikan Bahasa Indonesia, 1(1), 195203.

Piliang, W. S. H. (2016). Mekanisme pertahanan diri tokoh sentral dalam antologi cerpen Cerita Pendek Tentang Cerita Cinta Pendek karya Djenar Maesa Ayu (Kajian psikologi sastra). PEKA, 4(2), 164-170. 
Rohman, A. (2019). Mekanisme pertahanan ego tokoh utama dalam novel 3600 Detik karya Charon (Tinjauan psikologi sastra). SASTRANESIA: Jurnal Program Studi Pendidikan Bahasa dan Sastra Indonesia, 6(2), 26-40.

Sugiyono. (2017). Metode penelitian kuantitaif, kualitatif, dan R\&D. Bandung: Alfabeta.

Wiyatmi. (2011). Psikologi sastra teori dan aplikasinya. Yogyakarta: Kanwa Publisher.

Zaviera, F. (2007). Teori kepribadian Sigmund Freud. Yogyakarta: Prismasophie. 